\title{
REVIEW
}

\section{Bronchoscopic Management of Malignant Airway Obstruction}

\author{
Patrick D. Mitchell • Marcus P. Kennedy
}

To view enhanced content go to www.advancesintherapy.com

Received: March 12, 2014 / Published online: May 22, 2014

(C) Springer Healthcare 2014

\section{ABSTRACT}

Approximately one-third of patients with lung cancer will develop airway obstruction and many cancers lead to airway obstruction through metastases. The treatment of malignant airway obstruction is often a multimodality approach and is usually performed for palliation of symptoms in advanced lung cancer. Removal of airway obstruction is associated with improvement in symptoms, quality of life, and lung function. Patient selection should exclude patients with short life expectancy, limited symptoms, and an inability to visualize beyond the obstruction. This review outlines both the immediate and delayed bronchoscopic effect options for the removal of airway obstruction and preservation of airway patency with endobronchial stenting.

Electronic supplementary material The online version of this article (doi:10.1007/s12325-014-0122-z) contains supplementary material, which is available to authorized users.

P. D. Mitchell · M. P. Kennedy $(\bowtie)$

Department of Respiratory Medicine,

Cork University Hospital, Wilton, Cork,

Republic of Ireland

e-mail: marcus.kennedy@hse.ie
Keywords: Argon plasma coagulation; Brachytherapy; Cryotherapy; Malignant airway obstruction; Microdebrider; Photodynamic therapy

\section{INTRODUCTION}

Although bronchoscopy has progressed since 1897-when a German physician, Gustav Killian, removed a pork bone from the right main bronchus that had been aspirated by a Blackforest worker a bronchoscope he had created-the indications are similar (to diagnose and treat airway disease), the devices are similar (an illuminated scope, long and narrow enough to reach the airway), and the limitations are the same (the size of the scope as opposed to the reducing diameter of the airway) [1]. This was the beginning of modern bronchoscopy. Today bronchoscopy has developed into two distinct areas, diagnostic and therapeutic. Two types of bronchoscope are available: the rigid bronchoscope, developed by Chevalier Jackson in the 1920s; and the flexible bronchoscope, developed by Shigeto Ikeda in the 1960s, and this article will highlight the similarities and differences in these devices $[2,3]$. 
In the USA, lung cancer causes approximately as many deaths as the next four leading causes of cancer death combined [4]. Approximately 220,000 patients are diagnosed with lung cancer each year in the USA [4]. Onethird of lung cancers cause malignant airway obstructions (MAO) with associated symptoms [5]. Multiple metastatic malignancies can also cause MAO including thyroid, kidney, colon, esophageal, breast, and melanoma [see Video 1 in the electronic supplementary material (ESM)]. Symptoms of MAO include cough, dyspnea, hemoptysis, and symptoms related to post-obstructive pneumonia in patients with or without a prior cancer diagnosis. The target of treatment is to re-establish and/or maintain airway patency, achieve stability, and allow other cancer-targeted therapy with the intention of improving symptoms, quality of life, functional status, and lung function [5-8].

This review article is aimed at the respiratory physicians, especially those with a subspecialty interest in bronchoscopy. The contents reflect much of the current international guidelines [5-8]. The main focus of this article is for a comprehensive review of therapeutic bronchoscopy in the management of MAO.

This review article is based on previously conducted studies and does not involve any new studies of human or animal subjects performed by any of the authors.

\section{MULTIMODALITY APPROACH}

Patients with MAO should have a multidisciplinary team discussion in centers with expertise in the all possible interventions [6-8]. Interventions include bronchoscopic therapy, external beam radiation, and chemotherapy [6-8]. This article does not deal with treatment of MAO by external beam radiation which is covered in guidelines elsewhere [9]. This article will give an outline each of the immediate effect and delayed effect bronchoscopic modalities (Fig. 1; Table 1) for the treatment of MAO with a section dedicated to endobronchial stents. Bronchoscopic intervention is often multimodality with most centers offering a subset of modalities rather than all procedures available (Figs. 2, 3). Given the fact that bronchoscopic treatment of MAO is usually a palliative procedure in patients with advanced lung cancer, it is as important that trainees in bronchoscopy learn when and when not to intervene as it is to learn how to intervene. The target of intervention should include improvement in symptoms and quality of life, and not just to remove a visualized obstruction in the airway. In general, if the bronchoscopist cannot visualize normal airway beyond the obstruction on bronchoscopy or imaging, if life expectancy is short regardless of intervention, or if the patient has advanced cancer with little symptomatology due to immobility, bronchoscopic intervention should be avoided. It is also important to emphasize that no metaanalysis and limited prospective studies with objective measures are available on the role of multimodality therapeutic bronchoscopy. Two small studies of 37 and 20 patients identified improvements in dyspnea and quality of life, with documented improvements in lung function, after bronchoscopic treatment for MAO [10, 11]. Complication rates ranged from $3 \%$ to $8 \%$. Prospective data on long-term complication rates, such as infection and restenosis from multimodality approaches to $\mathrm{MAO}$, is also lacking. One recent retrospective study highlighted an increased risk of respiratory infections in patients undergoing airway treatment of MAO with as opposed to without stent insertion [12]. 


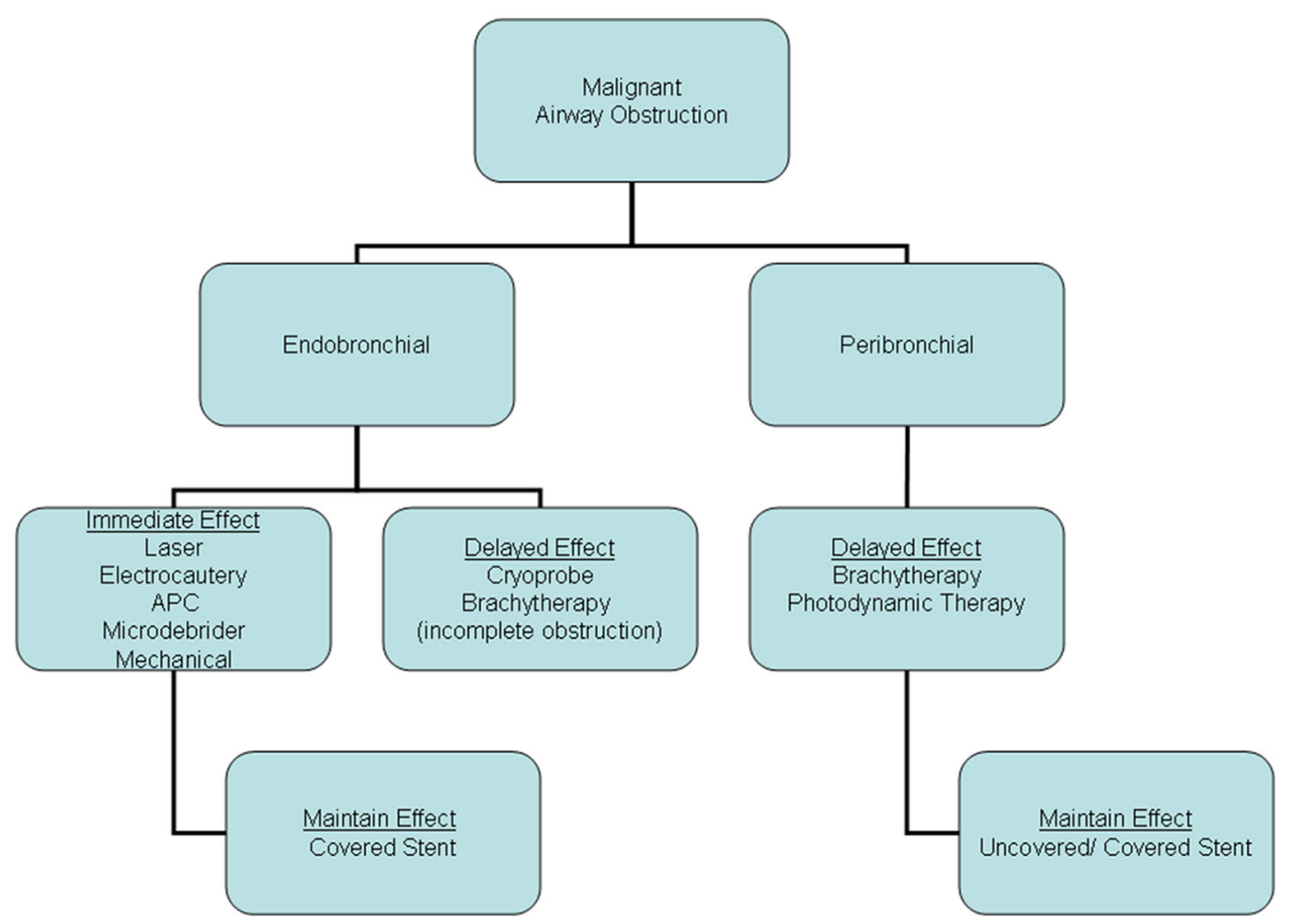

Fig. 1 Flow diagram of bronchoscopic options for malignant airway obstruction, $A P C$ argon plasma coagulation

Due to the fact that the majority of patients with MAO secondary to lung cancer have locally advanced or advanced disease, therapeutic bronchoscopic interventions are in the majority palliative and are rarely curative. Early assessment by a palliative care team in these patients improves outcomes [13]. Although most patients have locally advanced or advanced disease, MAO is not necessarily associated with poorer outcomes than locally advanced or advanced lung cancer without MAO. One study of 144 patients with locally advanced lung cancer compared 52 patients with MAO (treated with bronchoscopy plus chemotherapy and or radiotherapy) to 92 patients without MAO (chemotherapy) and showed no difference in survival (over approximately 8.4 months) [14]. In lung cancer patients with MAO who are operable, curative surgery is not contraindicated after bronchoscopic MAO treatment, although no randomized prospective trial is available. A study investigated 74 patients with non-small cell lung carcinoma (NSCLC) who required therapeutic bronchoscopy prior to surgery with curative intent. Patients underwent parenchymal sparing surgery (lobectomy or bilobectomy) in $57 \%$ cases and there were no deaths within 30 days [15].

\section{RIGID OR FLEXIBLE BRONCHOSCOPY}

Although comparisons will be made between both rigid and flexible bronchoscopy, both have their advantages in different scenarios but should be seen as complimentary procedures to each other [16, 17]. Rigid bronchoscopy is defined as the trans-oral or trans-tracheotomy passage of rigid instruments for diagnosis or 


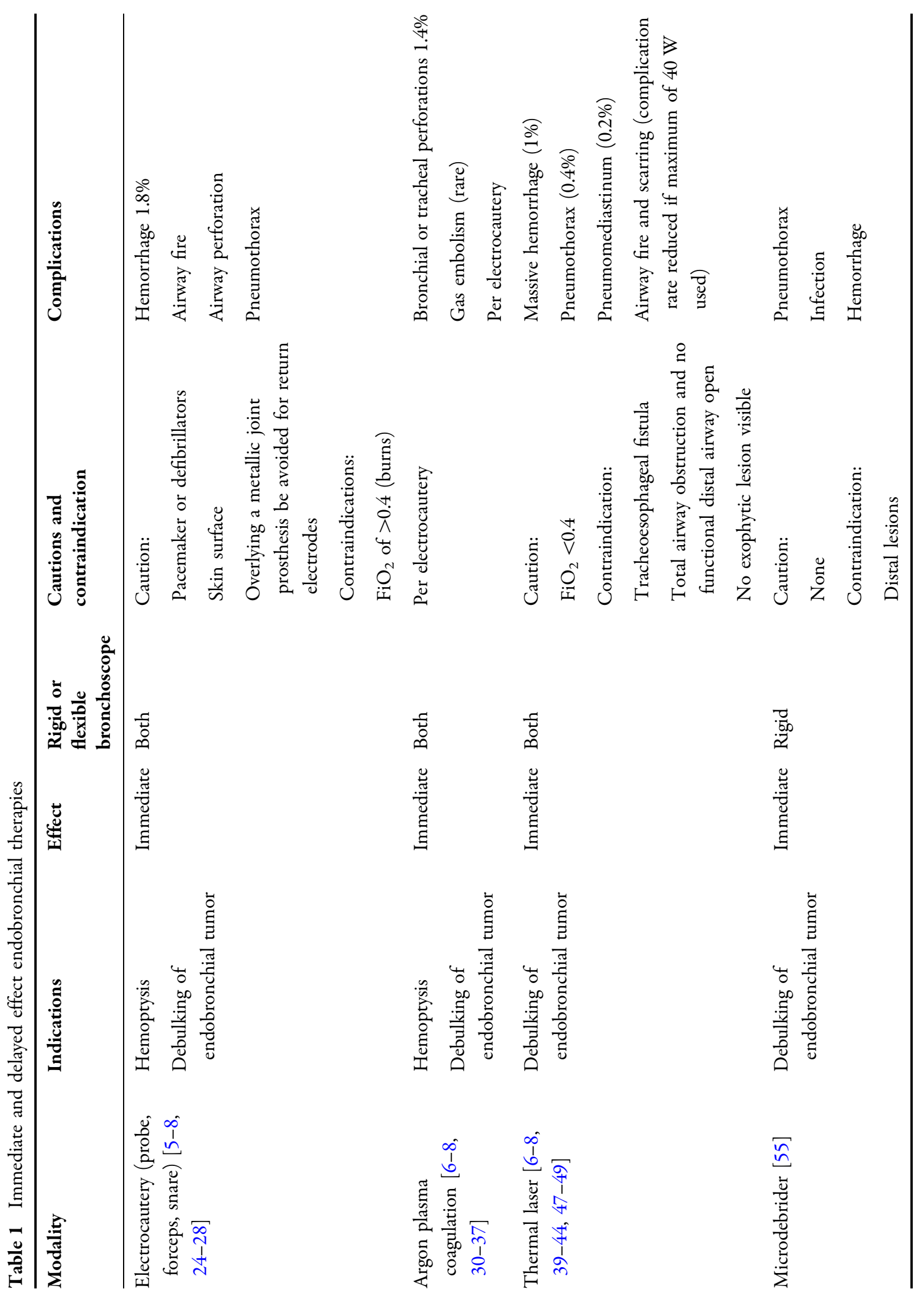




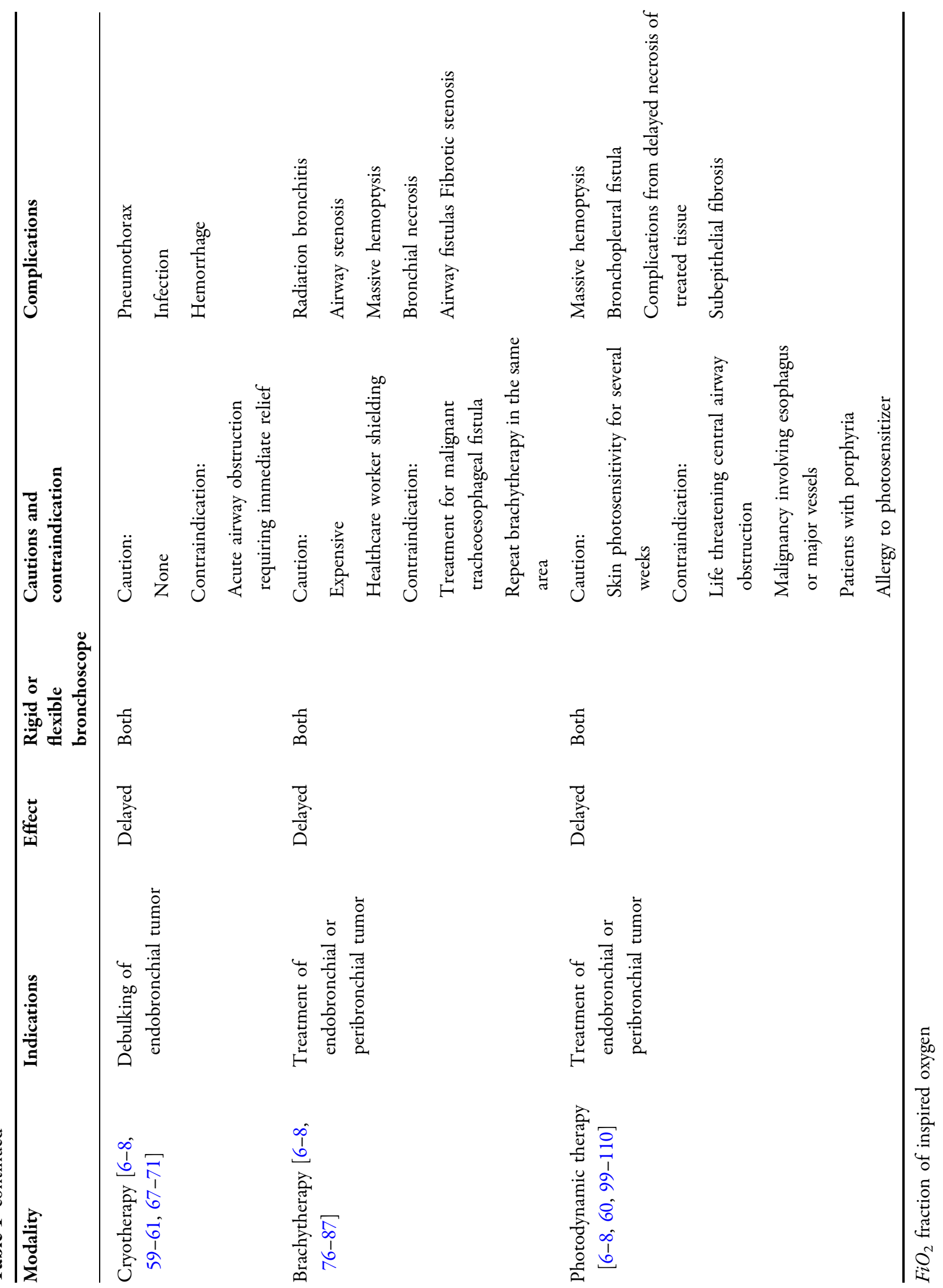



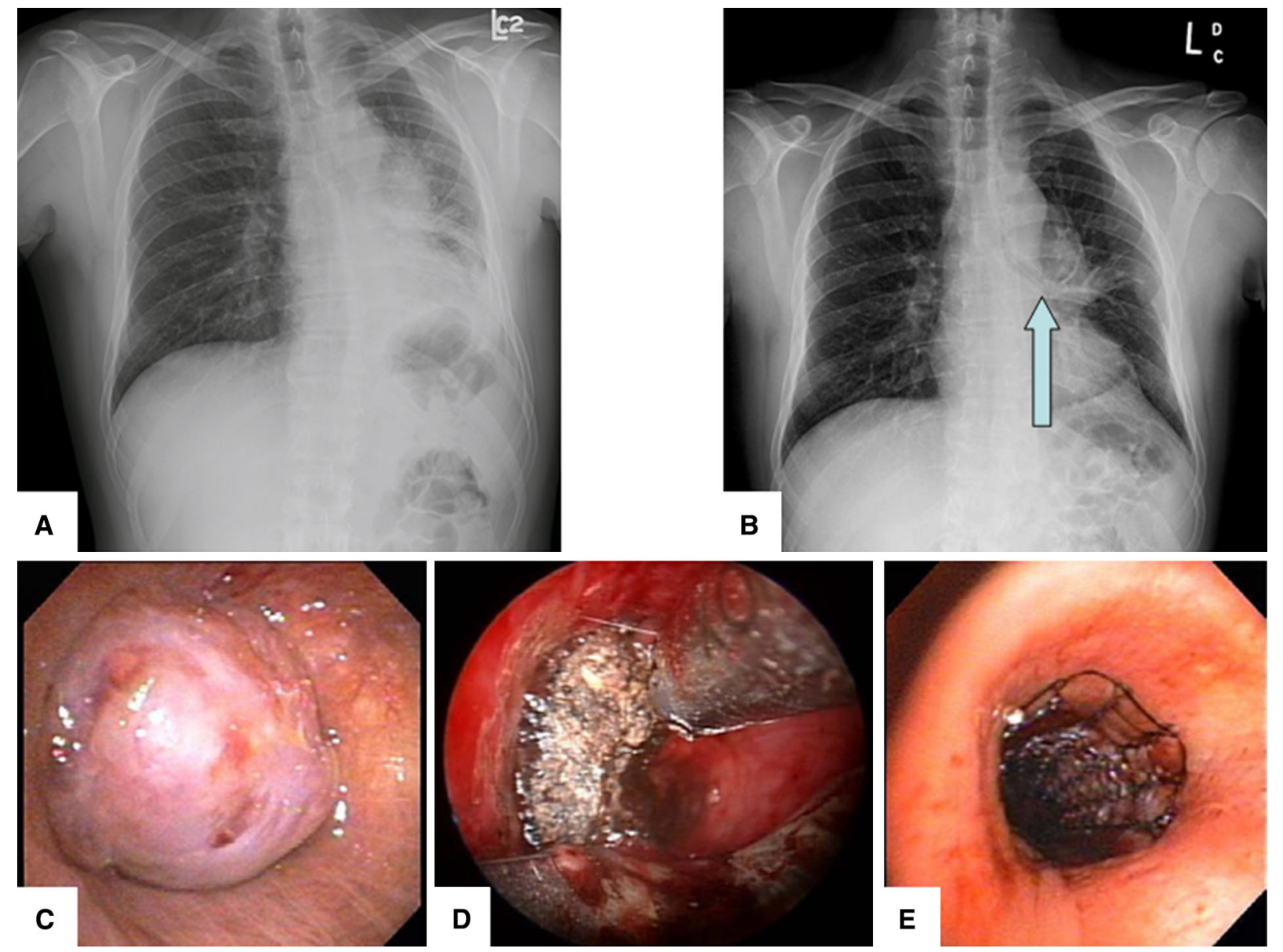

Fig. 2 53-year-old male with metastatic non-small cell lung cancer (reproduced with permission from Kennedy et al. [53]). Chest X-ray showing left hilar mass with loss of volume (a) relieved by bronchoscopic debulking and stent placement (blue arrow) with re-expansion of left lower lobe

(b). c Bronchoscopic image of left main bronchus endobronchial tumor. d Rigid bronchoscopic image of microdebridement of tumor post argon plasma coagulation. e Self-expandable metal stent in left main bronchus
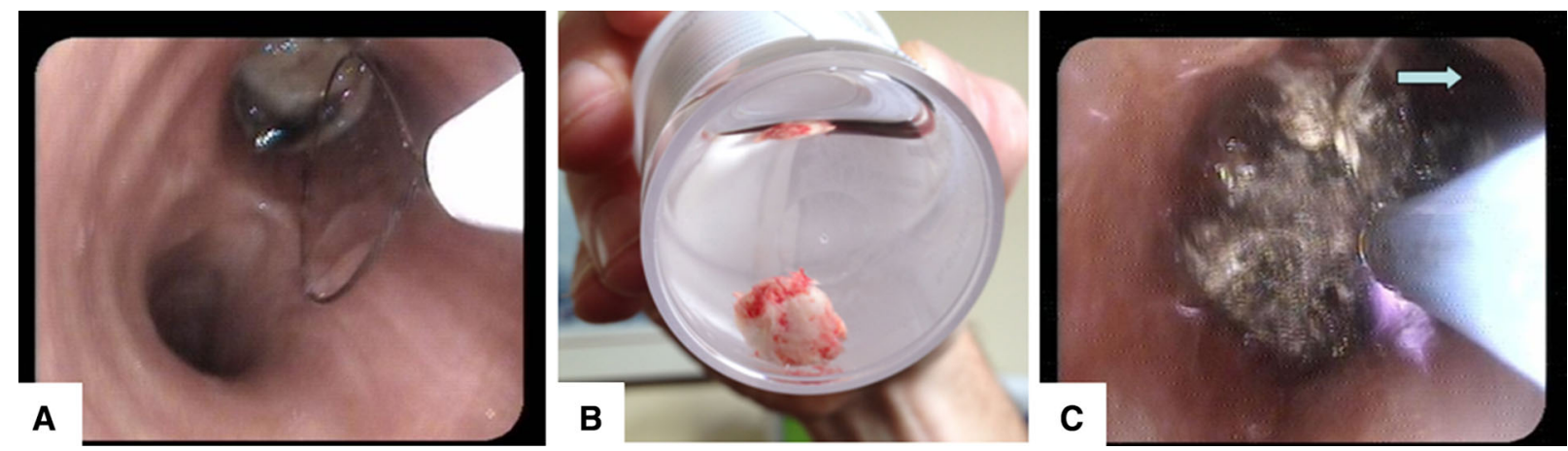

Fig. 3 64-year-old female with metastatic colon cancer. a Bronchoscopic image of endobronchial metastases in right main bronchus pre debulking with electrocautery snare. b Endobronchial metastases removed with electrocautery

snare. c Residual bronchus intermedius tumor treated with argon plasma coagulation with opening of right upper lobe bronchus (blue arrow) 
therapy, aided by various light sources, telescopes, and accessory instruments requiring a general anesthetic (Fig. 2). An operating theater is usually required for rigid bronchoscopy. Flexible bronchoscopy is defined as an invasive procedure that is utilized to visualize the nasal passages, pharynx, larynx, vocal cords, and tracheal bronchial tree, usually under conscious sedation [7]. When should the operator employ rigid or flexible bronchoscopy for MAO? An axiom to all bronchoscopy is where the operator is sufficiently skilled and has the support structures in place to carry out either procedure safely and efficaciously. In many parts of Europe and the USA, most respiratory physicians lack basic training in rigid bronchoscopy [6]. The vast majority of interventional techniques can be employed via a flexible bronchoscope. There are circumstances where rigid bronchoscopy is preferential (Table 2).

Contraindications to both procedures are uncommon (Table 2). Unstable patients, those with significant underlying cardiopulmonary disease, uncontrolled coagulopathy, and those with cervical instability (such as patients with rheumatoid arthritis), need to be carefully assessed. Mortality from flexible bronchoscopy is rare, with a reported death rate of up to $0.04 \%$ in 68,000 procedures $[17,18]$. Complication rates from rigid bronchoscopy are low at $0.1 \%$ [18]. Procedure-related mortality is rare [19].

Although guidelines do not favor rigid over flexible bronchoscopy in the management of MAO, the British Thoracic Society suggests all procedures not using rigid bronchoscopy be performed through a laryngeal mask airway or uncuffed endotracheal tube, allowing easy repeated insertion of the bronchoscope, high volume suction, and the deployment of balloon bronchial blockers [6]. In centers where bronchoscopists are restricted to the use of medications achieving standard conscious sedation, bronchoscopic management of MAO would, therefore, require anesthesiologist support and access to operating room facilities. However, many centers with expertise in MAO now utilize endoscopy suites structured to allow both standard and advanced bronchoscopy using rigid bronchoscopy with muscle relaxation and full anesthesia.

\section{INTERVENTIONAL BRONCHOSCOPY: IMMEDIATE EFFECT}

\section{Electrocautery}

Electrocautery was first used in the 1930s to treat rectal cancer [20]. Endoscopic electrocautery has subsequently found wide use in the treatment of gastrointestinal lesions, such as colonic polyps, bleeding vessels, and biliary stenosis [21]. Initial reports of the potential utility of electrocautery in the treatment of tracheal and bronchial tumors also appeared in the 1930s; however, high mortality and morbidity was associated with the procedure, secondarily to massive hemorrhage, infection, and tracheal perforation [21]. Electrocautery uses a highfrequency electrical current which causes a heating of the tissue structures that the probe is in contact with. At low voltages, temperature coagulation is achieved and at higher voltages, tissue vaporization. Most electrocautery devices used in endobronchial debulking employ a combination of cut and coagulation waveforms [22].

The equipment necessary is a high-frequency electrocautery generator (available in most hospitals) and relevant endoscopic instruments. An alternating current is applied between 105 and $107 \mathrm{~Hz}$. It is tissue resistance, 
Table 2 Rigid and flexible bronchoscopy in patients with malignant airway obstruction: indications, advantages, and complications

\begin{tabular}{|c|c|c|}
\hline & Rigid bronchoscopy & $\begin{array}{l}\text { Flexible } \\
\text { bronchoscopy }\end{array}$ \\
\hline \multicolumn{3}{|l|}{ Indications } \\
\hline Massive hemoptysis & ++ & + \\
\hline Tumor resection & ++ & ++ \\
\hline Deep bronchial-wall biopsy & ++ & + (cryoprobe) \\
\hline Stent placement & All stents & Self-expandable stents \\
\hline $\begin{array}{l}\text { Electrocautery, laser, cryotherapy, } \\
\text { brachytherapy, PDT }\end{array}$ & ++ & ++ \\
\hline Microdebrider & & ++ \\
\hline \multicolumn{3}{|l|}{ Advantages } \\
\hline Availability/training & Uncommon & Common \\
\hline Anesthesia & General anesthetic & Conscious sedation \\
\hline Reach & $\begin{array}{l}\text { Proximal airway (common practice is to pass a flexible } \\
\text { bronchoscope through rigid bronchoscope to reach } \\
\text { distal airways) }\end{array}$ & Proximal and distal airway \\
\hline Expense & ++ & + \\
\hline Suction & +++ & + \\
\hline Tools & Rigid, large & Flexible, small \\
\hline \multicolumn{3}{|l|}{ Specific complications } \\
\hline & Over sedation and hypoxia & $\begin{array}{l}\text { Those pertaining to general } \\
\text { anesthetic }\end{array}$ \\
\hline & Vocal cord trauma & $\begin{array}{l}\text { Dental, laryngeal edema/ } \\
\text { vocal cord trauma }\end{array}$ \\
\hline & & $\begin{array}{l}\text { Tracheal or esophageal } \\
\text { perforation }\end{array}$ \\
\hline
\end{tabular}

+ , minor indicator; ++ , moderate indicator; +++ , strong indicator; PDT, photodynamic therapy

which depends on vascularity, and moisture that generates the heat. The procedure is carried out under direct vision, with the electrode introduced within the tube of the rigid bronchoscope beside the optical system, or in the operating channel of the fiber-optic bronchoscope. The operator assesses the lesions to be treated, noting their position and the extent of malignant stenosis or extrinsic compression, whether they are projecting or infiltrating, and whether they are hemorrhagic or bland. The electrode must protrude from the end of the bronchoscope by about $2 \mathrm{~cm}$ and is then placed in contact with the lesions to be destroyed. The high-frequency generator is adjusted to automatic control of soft 
coagulation, with a power setting generally between 40 and $60 \mathrm{~W}$, or is adjusted to the visible coagulative effect if a first-generation machine is used. Two main methods of electrocautery are used: debulking of tissue by means of a cutting loop or electrocautery snare (Fig. 3), or direct electro-destruction of tissue using a probe, knife, or "hot" forceps. It is useful to clean the tip of the electrode frequently because buildup may damage the electrode and/ or reduce the delivered power. When undertaking snare resection, intermittent bursts of not more than $2 \mathrm{~s}$ should be applied. With malignant polypoid lesions, the electrocautery snare allows the removal or larger fragments of tumor without the requirement for complete tumor cauterization (see Videos 2, 3 in the ESM).

Both techniques are effective and provide good results. Tissue can be directly destroyed with electrocautery to achieve an effect similar to that seen with neodymium:yttriumaluminum garnet (Nd:YAG) laser vaporization, but is considerably cheaper [23]. Treatment is continued until sufficient patency of the airway lumen is restored and/or bleeding has arrested.

One case series, Sutedja et al. [22], described 17 patients with locally advanced tracheobronchial lung carcinoma who underwent endobronchial electrocautery; 15 patients had immediate reopening of the airway (88\%). There were no procedural fatalities. A prospective study evaluated the impact of bronchoscopic electro-surgery on the need for bronchoscopic Nd:YAG laser in patients with symptomatic MAO and observed that, of the 47 bronchoscopic electro-surgery procedures, 42 procedures (89\%) were successful in alleviating the obstruction, negating the need for laser. Each procedure was done under conscious sedation (morphine and midazolam) and topical anesthesia with lignocaine in the outpatient department [24].

The advantages of electrocautery are that it is relatively cheap, available and achieves immediate homeostasis and immediate relief of MAO. The disadvantages are that it requires a skilled user, physical contact is required, and there is a limit to the fraction of inspired oxygen $\left(\mathrm{FiO}_{2}\right)$ administered due to ignition of oxygen in the airway causing unintended trauma.

The complications of endobronchial electrocautery include that of general bronchoscopy. Application of deep electrocautery too close to the bronchial wall may result in perforation and pneumothorax. Cartilaginous rings may be destroyed, leading to a loss of structural support and the development of tracheomalacia or bronchomalacia. Electrocautery generates electric arcs and can cause tracheal fires or ignition of endotracheal tubes, fiber-optic bronchoscopes, or silicon endoprostheses. The risk of fire is increased if high fractions of inspired oxygen are used, which is why electrocautery is contraindicated if the $\mathrm{FiO}_{2}$ is above 0.4 . Hemorrhage from penetration of the probe into the tumor usually stops quickly with thermo-coagulation. Significant bleeding occurs in approximately $2 \%$ of cases and may be more common with vascular neoplasms such as carcinoid tumors (and hamartomas) [25-27]. Aspiration pneumonia, which is most likely due to aspiration of post-obstructive pus into the contralateral lung immediately after debulking, is a recognized complication. Electrical shock and/or electrical burns to the patient or operator may occur if unipolar leads and a non-grounded apparatus are used. Ventricular fibrillation has occurred when electrocautery is used near the heart [25], and interference with the function of implanted cardiac pacemakers 
or defibrillators may occur. It is best to seek advice from a cardiologist or the device manufacturer before performing electrocautery [25-27].

In summary, electrocautery, in experienced hands, is a safe, cheap, and effective therapy for early stage and advanced cancer with MAO [6-8].

\section{Argon Plasma Coagulation}

In interventional bronchoscopy, argon plasma coagulation (APC) has two main roles: to resect $\mathrm{MAO}$ and to control endobronchial bleeding (Figs. 2, 3). A simplistic description is that the beam of argon gas acts as a non-contact conduit for the electrocautery effect which distinguishes APC from electrocautery (see Videos 4, 5 in the ESM). The main effect of APC is tissue coagulation and has the advantage of minimal vaporization [28]. It has a penetration depth in human tissue of between 2 and $3 \mathrm{~mm}$. When using APC, a grounding pad should be placed on the patient's lower extremity. The patient should undergo flexible bronchoscopy and the target lesion should be identified. The usual energy applied is between 30 and $80 \mathrm{~W}$ and the argon gas flow rate should be from 0.3 to $2.0 \mathrm{~L} / \mathrm{min}$. Application time should be no more than $3 \mathrm{~s}$, without the tip actually making physical contact with the lesion or other healthy mucosa, to avoid unintended injury [28]. To ensure the bronchoscope will not be damaged, the APC tip should be at least $1 \mathrm{~cm}$ past the tip of the bronchoscope. So as the electrical current is conducted, the probe tip should be within $1 \mathrm{~cm}$ of the target lesion, again, ensuring it does not come into direct contact with either the lesion or healthy mucosa. Argon gas is expelled from the tip when activated and conducts a monopolar current through the target lesion causing heating [28]. Its immediate and superficial cauterization and non-contact requirement make it invaluable, if not the treatment of choice, in the treatment of localized non-massive hemoptysis caused by a malignant tumor [29]. There is a lack of evidence supporting APC as a treatment with curative intent for early stage malignant endobronchial disease, possibly due to its minimal depth of penetration [25, 30, 31].

Similarly to other electrocautery procedures, caution is advised in patients with cardiac pacemakers or defibrillators, and a cardiologists or manufacturer's opinion before the procedure is advisable. Patients requiring supplementary oxygen above a $\mathrm{FiO}_{2}$ of 0.4 should not undergo the procedure as there is a risk of ignition and airway burn. APC is not advisable where there is considerable or lifethreatening occlusion of the trachea as its penetration depth maybe insufficient. The complication rates are usually less than $1 \%$ [32-34]. These complications include the usual risks of bronchoscopy, airway burns, airway perforation, pneumomediastinum, and pneumothorax or gas embolism. Gas embolism is a unique and rare complication of APC and this may be the result of sustained application of APC towards an area of rigorous bleeding. Gas embolism has also been described in which a death occurred [33]. It led to three cases of cardiovascular collapse (possibly through bronchial veins) [33].

There are no published trials that compare the various interventional bronchoscopic modalities for MAO. Thus, current practice is based upon the availability of resources and equipment, the bronchoscopists training, and latest best practice. Reichle et al. [34] described a total of 364 patients having 482 APC procedures (90\% via rigid bronchoscopy) with a success rate of $67 \%$. Success in this study was defined as hemostasis and/or full or partial airway 
recanalization [34]. Morice et al. [35] described in a retrospective cohort study of 60 patients who underwent APC for MAO with hemoptysis a success rate of $98 \%$. The author considered APC superior to electrocautery and laser photoresection in achieving hemostasis [35]. Crosta et al. [36] found that $92 \%$ of 47 patients treated with APC achieved airway recanalization and localized hemostasis. APC has been used in the setting of metastatic disease, for example, malignant melanoma, to recanalize airways [37].

In summary, APC is a cheap, safe, and effective modality for treating both MAO and hemoptysis [6-8].

\section{Laser}

The use of laser in bronchoscopy started almost three decades ago when Strong and Jako in 1972 used a $\mathrm{CO}_{2}$ laser to treat various laryngeal disorders and the following year went on to use this modality to treat endobronchial lesions [38]. Bronchoscopic laser resection is a useful modality in the treatment of MAO, particularly exophytic proximal airway lesions. Airway obstruction, secondarily to bronchogenic carcinoma, is the most frequent indication for laser resection $[39,40]$. It may also be employed for a metastatic tumor that presents similarly to primary bronchogenic tumors. Its role, like electrocautery and APC, is redundant where there is extrinsic compression. Thermal laser resection can be easily and safely combined with other methods of bronchoscopic treatment, including electro-surgery, stenting, and brachytherapy. There are many different formats of medical lasers. The Nd:YAG laser is the most commonly used laser for bronchoscopic laser resection. The Nd:YAG lasers energy is delivered through flexible fibers that are inserted through either a rigid or flexible bronchoscope $[39,40]$. The tumor is removed through two applications:

1. Resection: The laser is aimed at the target lesion and through photocoagulation of the feeding blood vessels and amelioration of the lesion the devitalized tissue is removed through the bronchoscope. Penetration depth and photocoagulation can be up to $10 \mathrm{~mm}$ in an inverted cone pattern.

2. Vaporization: Vaporization involves aligning the laser parallel to the bronchial wall and aiming at the edge of the intraluminal lesion. Laser pulses should be limited to $1 \mathrm{~s}$ or less. This is possible because the energy from the laser is relatively well absorbed by water. Vaporization requires higher power and, therefore, heats the affected tissues more than resection. It is essential that the laser be used in parallel with the target lesion, and not straight on or perpendicular, to reduce the chances of perforation.

Resection is preferentially performed with rigid bronchoscopy as this facilitates the removal of large amounts of debris [41]. Flexible bronchoscopy may be used if the airway abnormality is within a distal segmental bronchus. Indeed, flexible bronchoscopy allows removal of smaller, more distal fragments of pathological tissue that rigid bronchoscope may fail to reach, especially upper lobe tumors. Tissues that look highly vascular or charred from previous endobronchial therapies need to be viewed with caution and probably should be avoided because the dark color enhances tissue absorption. The increasing absorption reduces the depth of tissue penetration causing a reduction in the effectiveness of the thermal ablative effect. Regarding moderate-to-large sized lesions, thermal laser vaporization 
requires high tissue energy deposition which may cause unintended perforation and burns, a recognized complication. Precautions during laser resection include wearing protective goggles, protecting the patient's eyes with saline-soaked pads and aluminum foil to avoid injury from accidental laser scatter. It is imperative that the $\mathrm{FiO}_{2}$ be kept below 0.4 so as to avoid combustion in the airway. This, of course, precludes patients requiring supplemental oxygen above this threshold. All potentially flammable materials should be kept far away from the field of the thermal laser. Silicone stents should always be removed prior to laser use. The laser should always be placed on standby mode while tissue is removed from the bronchoscope. It is essential to have adequate suction available to remove the smoke from thermal burning as it can be combustible. The power settings should not exceed about $40 \mathrm{~W}$ for the Nd:YAG laser to reduce the risks of perforation and fire $[42,43]$. Complications of thermal laser include those pertaining to bronchoscopy. Thermal laser can cause airway hemorrhage, burns, perforation, pneumothorax, and, rarely, arterial air embolism, which may cause a cerebrovascular accident or myocardial ischemia [41-44]. Thermal laser is an effective modality in the treatment of malignant endobronchial lesions. For the past four decades, the outcome data regarding bronchoscopic laser resection has been very encouraging. It appears to be an immediate and relatively safe way to manage malignant endobronchial lesions $[45,46]$. A large study by Cavaliere et al. [47] in 1988 demonstrated the effectiveness of thermal laser in managing malignant endobronchial tumors. A rigid bronchoscope was used in 1,280 (92\%) of the treatments, with patients almost always under general anesthesia; $116(8 \%)$ treatments were performed with the flexible fiber-optic bronchoscope alone, with the use of local anesthesia. In almost all cases of localized carcinoid tumors, the treatment was curative [47]. Another case series by Cavaliere et al. [48] demonstrated that airway patency and symptoms were improved in over $90 \%$ of cases, and mortality was less than $1 \%$. Nd:YAG laser intervention is safe and effective for palliation of endobronchial malignancies. In most cases, it only needs to be performed once [48]. Compared with Nd:YAG laser therapy alone, multimodal treatment, which includes stent insertion, brachytherapy, chemotherapy, and radiotherapy together with Nd:YAG laser therapy, has demonstrated prolonged survival, suggesting the benefits of a combined approach [49]. One study of 99 patients with MAO demonstrated an improvement in dyspnea, lung function, and performance status in patients with partially occluded airways, but it was felt that physicians underestimated the severity of patients symptoms compared to the patients themselves which must be borne in mind when interpreting symptomatic relief statistics [50].

A cheaper endobronchial laser is now available [neodymium:yttrium-aluminum perovskite (Nd:YAP)]. Thus far, there are limited data on the usefulness of this laser in MAO; however, applications and complications are similar to the Nd:YAG laser. One study of 133 patients with various malignant and benign (7 patients) indications concluded that the Nd:YAP laser was a safe and effective tool for bronchoscopy [51]. No direct comparisons are available.

In summary, laser through bronchoscopy is an effective approach for treatment MAO. ND:YAG laser is more expensive, may not be available in many centers, and requires training in safety to prevent injury to patients and staff [6-8]. 


\section{Microdebridement}

The microdebrider has been used for nearly 30 years by otorhinolaryngologists for upper airway endoluminal lesions including laryngeal carcinomas [52]. A microdebrider operates by using a powered rotating blade and a simultaneously operating suction device to facilitate the removal of debris. A recent case report demonstrated excellent results with an elongated rotating tip microdebrider to about $45 \mathrm{~cm}$ (Fig. 2) [53]. The advantages of microdebridement are that it is accurate and allows high flow oxygen which is contraindicated in other thermal ablation procedures, such as APC, thermal laser, and electrocautery. However, APC or electrocautery may be required to achieve hemostasis. Microdebridement has been shown in a retrospective analysis of 23 patients to be successful treatment of tracheal granulation tissue, idiopathic subglottic stenosis, and MAO [54]. The complications of thermal modalities, such as airway injury, tracheoesophageal fistulas, and airway fires, can be avoided using microdebridement. The main complications of microdebridement are those pertaining to bronchoscopy, hemorrhage, perforation, and pneumothorax [55].

\section{INTERVENTIONAL BRONCHOSCOPY: DELAYED EFFECT}

\section{Bronchoscopic Cryotherapy}

First described in 1812 to help achieve hemostasis and analgesia in surgical amputee during the Russian campaign, cryotherapy is a cheap and effective treatment for many medical conditions $[56,57]$. Bronchoscopic cryotherapy

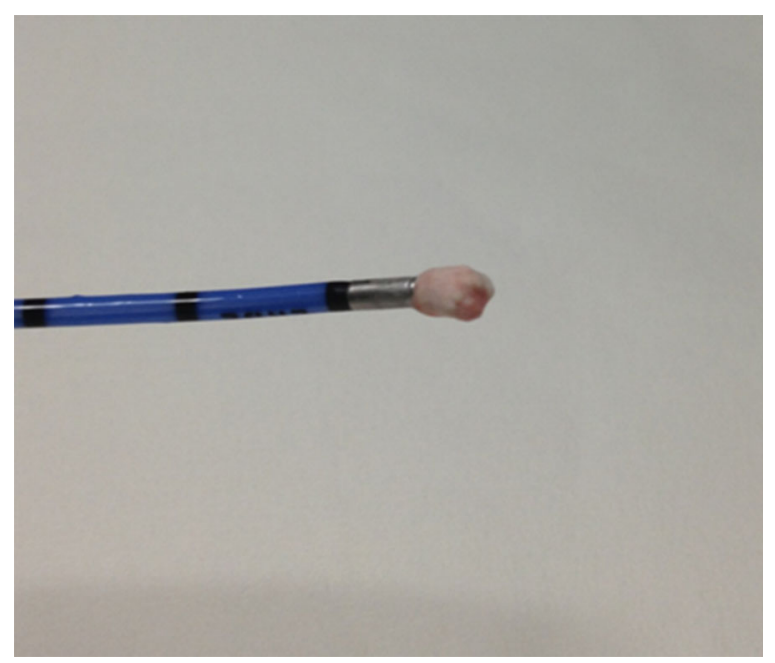

Fig. 4 70-year-old male with non-small cell lung cancer. Large endobronchial tumor fragment removed with cryoprobe (blue)

is an interventional bronchoscopic procedure where, either through rigid or flexible bronchoscopy, malignant or benign tissue is ablated by repeatedly freezing, thawing, and refreezing (Fig. 4). The first reported use of bronchial cryotherapy was by Sanderson et al. [58] in 1975. The mechanisms of cryotherapyinduced cytotoxicity are well established. The tissue destruction caused by cryotherapy causes a coagulative necrosis in a tumor. The initial freezing of target tissue causes it to stick to the probe. Following this there is both extracellular and intracellular ice formation which causes disruption of cellular enzymes and cell membrane integrity. When the cell thaws water returns to the cell quickly (at freezing the extracellular region becomes hypertonic causing water to move out of the cell). This rapid return of intercellular water causes cell lysis $[59,60]$. The area of destruction through cryotherapy has a diameter of $1 \mathrm{~cm}$ when a 3-mm diameter probe is used. When in lateral contact with a bronchial wall, cytotoxicity can be considered complete to a depth of $3 \mathrm{~mm}$ [59, 60]. Non-hemorrhagic necrosis of the tissue 
occurs 8-15 days following the procedure [61]. Collagen, cartilage, or poorly vascularized tissues are very cryo-resistant. Indirect damage to blood vessels below $3 \mathrm{~mm}$ further adds to the destruction of the target lesion (blood vessels above $3 \mathrm{~mm}$ are protected by the warming effects of blood flow). Cryotherapy does destroy a margin of normal tissue surrounding the tumor as well as the tumor itself [62]. The vast majority of tumor cells are destroyed at $-20^{\circ} \mathrm{C}[7,62]$. Increased cell death is proportional to the amount of time at which the low temperatures are maintained, but this increases complication rates $[59,60]$. The recommended temperature is $-40^{\circ} \mathrm{C}$ as this will destroy the tumor cell line that might be resistant to destruction at $-20^{\circ} \mathrm{C}[60]$. A repeat bronchoscopy needs to be performed to remove necrotic debris about 3-6 days later. There is another newer method, cryoextraction, which employs an endotracheal airway to remove tissue at the time of cyroablation. Cryoextraction causes immediate results and so could be used to treat acute tracheal or bronchial obstruction [63, 64]. There are two types of probes available: a liquid nitrogen probe, which is very powerful but awkward to use, and a nitrous oxide $\left(\mathrm{N}_{2} \mathrm{O}\right)$-driven cryoprobe. Flexible cryoprobes of $2-3 \mathrm{~mm}$ in diameter are available and can be used through a flexible fiber-optic bronchoscope [65]. Usually, between 3 and 30 treatments, each lasting $20 \mathrm{~s}$, are required. The procedure is relatively painless. About 1-2 weeks after cryotherapy, necrotic tissue is sloughed off and expectorated or removed if a repeat bronchoscopy is performed.

The effects are excellent with a wellvascularized tumor such as carcinoid and carcinoma. Vergnon et al. [60] reports a cure rate of $100 \%$ in endobronchial carcinoid treated with both laser-assisted mechanical resection followed by cryotherapy. Cryotherapy has also been indicated for in situ carcinoma where cure is the intention [66]. Cryotherapy may also be indicated for and has been used in the treatment of low grade malignant tumors such as lymphoma, adenoid cystic carcinoma, and in carcinoma in situ [66-68]. Cryotherapy has been used in a case series in patients with endobronchial carcinoid tumors [63]. It has also been utilized against metastatic deposits in the main airway. It is very effect in controlling hemoptysis secondarily to its remarkable effect on tumor vascularization [11, 69]. Seon-Heui et al. [70] described a review of 16 publications of patients who underwent cryotherapy for the treatment of MAO. Overall success rates for significant recanalization of the obstruction were approximately 80\%, although they varied, depending on disease status in the patient population. Complications from the procedure developed in $0.0-11.1 \%$ of cases, most of which were minor and controlled by conservative management [70]. In another study of over 400 patients who had cryotherapy for obstructive tracheobronchial tumors, significant symptomatic relief was achieved in $76.4 \%, 69.0 \%, 59.2 \%$, and $42.6 \%$ of patients with hemoptysis, cough, dyspnea, and chest pain, respectively [71]. The KaplanMeier median survival was 8.2 months and 1 - and 2-year survival rates were $38.4 \%$ and $15.9 \%$, respectively [71].

The complications related to the procedure are the usual risks pertaining to bronchoscopy. Hemoptysis (which can occur $48 \mathrm{~h}$ after the procedure), bronchospasm, cardiac arrhythmia, and death have been reported in about $1.5 \%$ of cases [59, 60, 69-71]. However, in one recent case series, Schumann et al. [66] described significant bleeding requiring APC in $8 \%$ of patients undergoing cryotherapy. Another complication experienced is that of a transient 
flu-like illness following cryotherapy, which may be due to the release of tumor cell cytokines such as tumor necrosis factor [65]. A delayed complication is when the sloughed-off necrotic tissue causes dyspnea and cough. No absolute contraindications exist but where there is a life threatening airway obstruction more immediate management is required than endobronchial cryotherapy [72].

In summary, cryotherapy may be considered for MAO in patients without critical airway narrowing. Its main advantage, in a similar to fashion to microdebridement, is that there is no limitation in oxygen delivery during the procedure [6-8].

\section{Brachytherapy}

Endobronchial brachytherapy (EB) is an invasive two step technique. The first step in brachytherapy is to identify the target lesion and the second step is to remotely, under fluoroscopy and computer guidance, place the radioactive source (usually $1 \mathrm{~mm}^{3}$ in size) beside the target lesion, and also involves minute changes in its position in a staged process to allow irradiation on the target lesion. Yankauer [73] first described the use of EB in the 1920's in two patients. A capsule impregnated with radium was placed, using a rigid bronchoscope, in endobronchial tumor and removed several days later via an attached string. Pancoast [74] also described the technique over the next two decades with most cases done under general anesthetic via rigid bronchoscopy or thoracotomy. The next major advance occurred in 1964, when Henschke et al. [75] developed the remote after loading device which reduced the radiation exposure to healthcare staff in 1964. In the 1980's, the radioactive isotope iridium192 became the isotope of choice for brachytherapy due to its small size and its high radiation activity (approximately $10 \mathrm{~Gy}$ at the beginning). Iridium-192 is the most common isotope used because it permits a dramatic reduction of treatment time, reduces costs, enhances the patient experience, and allows for an outpatient setting over several sessions [5]. "Low dose rate" (LDR) has been distinguished from "high dose rate" (HDR) brachytherapy [76]. LDR brachytherapy is less than $2 \mathrm{~Gy} / \mathrm{h}$ and a maximum of $1,500-5,000$ cGy over 3 days. It requires inpatient treatment for up to 3 days and is costly and cumbersome with radiation protection measures. HDR is about $12 \mathrm{~Gy} / \mathrm{h}$ with the dose varying from 100 to $300 \mathrm{cGy}$ (calculated at $10 \mathrm{~mm}$ from the source axis). HDR allows placement through the tip of a hallow catheter to the tumor site for a much shorter period of time which is less costly than LDR and enhances the patient experience [76, 77].

Upon decision of type of brachytherapy and identification of lesion, the irradiated length is marked by external tags controlled by fluoroscopy. A guide wire is placed through the bronchoscope and the irradiation applicator is placed over this by the Seldinger technique [76]. A dummy seed in first placed and its position is confirmed with a set of orthogonal chest radiographs. Once correct positioning has been confirmed the applicator is connected to the Iridium-192 source and then advanced down to the target lesion. When in place the radiation source is moved in $5 \mathrm{~mm}$ intervals in periods of time decided on by oncology algorithms at the lesion site [78, 79]. High doses of radiation can be safely administered with little collateral damage to healthy surrounding tissues [80]. Follow-up bronchoscopy is advised 3-6 weeks after treatment. EB was initially dedicated to a 
palliative setting; with symptoms improving in $60-88 \%$ of procedures and an endoscopic response rate of $30-100 \%$ [81]. The benefits of EB over external beam radiation are the precision targeting of a lesion with larger dosage of radiation and the limiting of damage to surrounding tissues. A report has also described the use of a modified airway stent to approximate brachytherapy catheters to a carinal lesion [82].

The major use of EB is for the palliation of symptoms related to MAO. It is not indicated to achieve immediate debulking effects. Some investigators have reported that $70 \%$ of patients have greater than 50\% improvement in patency that persists for at least 6 months $[83,84]$. However, the characteristics and follow-up in these series of reports is varied. The subjective symptom relief varies widely with case series and a Cochrane review quoting figures from $20 \%$ to $100 \%$ of patients gaining some form of relief [83-85]. An observational study of 175 patients reported by Kelly et al. [86] in patients with lung cancer who received HDR brachytherapy for metastatic or locally recurrent disease, demonstrated symptomatic improvement in 115 patients (66\%). A further post-HDR bronchoscopy found that $78 \%$ of these patients had responded to therapy, defined as at least 50\% reopening of the normal lumen [86]. Treatment-related complications were detected in only 19 patients (11\%). Interestingly, those who gained a symptomatic benefit lived statistically longer than those who did not. Hemoptysis tends to improve most readily, with a greater than $90 \%$ response rate in many series [86]. Cough and dyspnea improve less reliably with HDR. Brachytherapy has been used with curative intend, near universally in those patient unsuitable for surgery. In a French series of 226 patients with non-small cell bronchial carcinoma (97\% had squamous cell carcinoma) who were not candidates for surgery or external beam radiation therapy (EBRT) the 2 - and 5-year overall survival rates were 57\% and $29 \%$, respectively, while the 2- and 5-year cancer-specific survival rates were $81 \%$ and $56 \%$, respectively [87]. HDR brachytherapy was associated with a complete endoscopic response rate of $94 \%$ at 120 days [87]. A 2008 Cochrane review of palliative EB for NSCLC analyzed 13 randomized controlled trials but could not combine them into a meta-analysis because of heterogeneity in the doses of radiotherapy delivered, patient characteristics, and outcomes measured [85]. The authors concluded that EBRT alone is still more effective for palliation of symptoms than EB alone. Their findings did not provide conclusive evidence that EB plus EBRT improved symptom relief over external beam radiation alone, nor did it improve complication rates or extend survival. In summary, the authors were not able to provide conclusive evidence to recommend EB as an add-on to first-line EBRT, chemotherapy or Nd:YAG laser palliative treatment [85]. For patients previously treated by EBRT who are still symptomatic, EB may be considered an option [85, 88]. Indeed there is some evidence to support the addition of EB to EBRT for local control [88, 89]. Two randomized trials compared EB to EBRT with or without EB. Improvements in the combined modality were identified in the arm of one trial and were short lived. The second trial identified that both EB and EBRT improved symptoms, with EBRT performing better but with more acute morbidity. The rate of fatal hemoptysis was high at $7-15 \%[90,91]$.

Complications of EB include those of regular bronchoscopy. Initially, patients may complain of increased bronchial secretions and severe cough. Patients with poor performance status 
are at higher risks of respiratory failure [85]. Some patients experience pleuritic chest pain. Airway perforation, causing pneumothorax or mediastinitis, can occur. As with external beam radiation treatment radiation bronchitis and bronchial stenosis is a recognized complication. The most important complications are fistula formation and massive hemoptysis with a prevalence of $10 \%[76,84,85]$. There exists evidence that squamous cell carcinoma of the main stem bronchi is a risk factor for fatal hemoptysis [92].

Contraindications to EB include patients with high-grade occlusive endotracheal or proximal bronchial lesions as the treatment causes edema which could lead to lifethreatening airway obstruction. EB is also proscribed in patients with imminent danger of fistula formation between the airway and other structure. Patients with a high level of airway obstruction should be treated with either Nd:YAG laser and/or stent placement before brachytherapy. EB is relatively contraindicated in patients who have a life expectancy of less than 3 months [76, 84, 85].

In summary, brachytherapy is effective in the palliation of both endobronchial and peribronchial malignancy with a delayed effect. There is a significant risk of hemoptysis [6-8].

\section{Photodynamic Therapy}

Modern oncologic treatment by drug-light interactions dates back to 1903 in treating skin cancers [93]. Photodynamic therapy (PDT) has a long and successful clinical track record for both malignant and benign conditions (acne vulgaris or hemorrhagic hereditary telangiectasia) [94, 95]. Bronchoscopic PDT was first used with success in Japan in 1982 in a patient with lung cancer who refused surgery [96]. That patient died 4 years later from an unrelated cause [96]. In lung cancer, the indications for PDT are management of an early endobronchial cancer defined as visible on bronchoscope viewing but not on radiological imaging and in advanced disease where palliation and symptom control is needed. In cancer biology, tumor cells preferentially take up certain photophilic porphyrin-based bloomers. The most commonly used substance is a hematoporphyrin derivative (HPD). These photophilic porphyrin-based oligomers substances, when exposed to light of a particular wavelength, trigger a cytotoxic reaction killing tumor cells, inducing apoptosis, and disrupting angiogenesis [97-99].

In lung cancer patients, a photosensitizing agent is intravenously applied [2-4 mg/kg of Photofrin $^{\circledR} \quad$ (Jubilant Hollisterstier General Partnership, Pinnacle Biologics Inc., USA)] and allowed time to preferentially accumulate in the tumor region [99]. The drug is cleared from most organ systems within $72 \mathrm{~h}$, but is retained longer in tumors, skin, and the liver for up to 30 days. Usually, the PDT is applied about $48-72 \mathrm{~h}$ after the intravenous injection to allow the photosensitizing material to accumulate in the target lesion and wash out of healthy tissue, reducing collateral damage to non-malignant tissue [100]. Light of a selected wavelength and intensity is employed to activate a particular photosensitizer that has accumulated in the target lesion. This leads to permanent lesion destruction. The light absorption spectrum is at about a wavelength of $405 \mathrm{~nm}$ for the porphyrin-based oligomer. At this wavelength, the light is completely absorbed at the tissue surface and only causes superficial tumor destruction. A wavelength of $630 \mathrm{~nm}$ achieves greater tissue penetration and is used for therapeutic applications and results 
in tumor destruction to a depth of $5-10 \mathrm{~mm}$. The most commonly used light sources are argon-pumped or potassium-titanyl-phosphatepumped tunable dye lasers, which emit a nonthermal laser light [101, 102]. The light can be delivered through one of several types of fiber systems, which can be introduced via the working channel of a flexible bronchoscope. The most commonly used design is a cylindrical diffuser which differs from conventional laser fibers by emitting the light laterally in a $360^{\circ}$ arc close to the tip. The chosen tip length depends upon the length of the lesion. Treatment with laser light is non-thermal; therefore, the effect of PDT is delayed, usually by 2 days. Total energy delivery depends upon the timing of treatment after injection of the sensitizing agent and the energy delivered through the fiber-optic scope. It is recommended initially to apply $200 \mathrm{~J} / \mathrm{cm}$ treated; additional energy may be applied during a follow-up bronchoscopy 48-72 h later. Neovascular endothelium found in tumors seems particularly susceptible to PDT, with loss of capillary integrity soon after treatment reducing the blood supply to the tumor. PDT is usual performed safely and conveniently with the flexible bronchoscope and mild sedation. Rigid bronchoscopy is reserved for the unstable or hypoxic patient or those undergoing prolonged and complex procedures. Topical anesthesia is compulsory to eliminate coughing which can dislodge the positioning of the PDT probe. The nasal route is preferable as the bronchoscope can more easily be held in a fixed position during light application. Once the tumor is visualized, the rigid cylindrical tip should be embedded into the lesion thereby improving the targeted delivery of PDT. The light treatment can then be employed [103-105]. After suctioning all secretions, the bronchoscope is removed. A repeat bronchoscopy is usually performed $48 \mathrm{~h}$ later, when the inflammatory response is particularly prominent, and the resulting secretions can cause airway compromise. Patients must be informed that they will be photosensitive and at risk for sunburn immediately following the injection and for 4-6 weeks after. Sunscreen does not provide protection and patients need to be well informed that they must cover with clothing as much skin as possible. Light from most artificial light sources and from televisions does not pose problems [105-107].

PDT has been used cure early stage endobronchial lung tumors as well as the ability to palliate central endobronchial obstruction [60, 103-107]. PDT has also been used with success to treat superficial occult shallow lesions, local recurrence, distal endobronchial obstruction, endobronchial metastases of non-pulmonary malignancies, and hemoptysis from an endobronchial arteriovenous malformation $[60,106]$. One study of 133 patients with obstructive airway lesions led to an improvement in dyspnea and hemoptysis in $74 \%$ and $99 \%$ of cases, respectively [51]. Photodynamic therapy may be considered as an alternative treatment for patients under consideration for surgical treatment for stage I carcinoma in whom the risk of surgery is high [108]. Diaz-Jiménez et al. [109] compares the efficacies of PDT and $\mathrm{Nd}$ :YAG laser therapy for the palliation of symptoms caused by malignant endobronchial obstruction. Their results for both modalities appear to be similar when directly compared in patients with inoperable NSCLC [109]. The advantages of PDT over Nd:YAG laser therapy is it does not produce endobronchial smoke and can be performed in an oxygen-rich environment (i.e., hypoxic patients requiring supplementary oxygen). PDT has been successfully combined with other 
endobronchial therapies, including brachytherapy and laser therapy [60, 109-111].

The complications of PDT are those of routine bronchoscopy and those specific to PDF. Certainly, sunburn up to 6 weeks post HPD administration is a concern and patients need to be fully informed to avoid sunlight and to wear appropriate clothing. Sunscreen has little if any benefit. Other complications are hemoptysis, bronchopleural fistula formation, fibrotic stenosis, and bronchial necrosis. PDT is contraindicated in patients with an allergy to the photosensitizer, patients who have porphyria, and in those patients with lifethreatening obstruction or malignancy involving any major blood vessels or the esophagus.

In summary, PDT is effective in debulking and palliation with delayed effect and no limitation of oxygenation in MAO [6-8].

\section{Airway Stents}

Airway stents, also known as tracheobronchial prostheses, are tube-shaped devices that are inserted into an airway to maintain airway patency. Airway prostheses or stents made of metal, silicone, or other materials can be used to relieve airway obstruction caused by malignant tumors (Fig. 2; Table 3) [112]. Stent therapy is indicated in both intraluminal and extraluminal major airway obstructions. Depending on the stent type, they can be placed by either rigid or flexible bronchoscopy. The ideal tracheobronchial stent has not been developed yet. Ideally, it would combine the advantages of silicone and metallic stents. It should be easily inserted and removed and designed to prevent migration, tumor ingrowth, and allow mucociliary clearance [113]. Silicone stents require rigid bronchoscopy and, therefore, a general anesthetic, whereas metallic stents can be placed under conscious sedation via a flexible bronchoscope. Hybrid stents can be placed either through rigid or flexible bronchoscopy $[6,114,115]$.

Stents can be used in both benign and malignant disease. For lesions with both extrinsic compression and endobronchial tumor, a stent incorporating a covering membrane ('covered stent') is favored to prevent tumor ingrowth through the stent. Endotracheal or endobronchial stenting can

Table 3 Advantages and disadvantages of different airway stents

\begin{tabular}{lll}
\hline Stent type & Advantages & Disadvantages \\
\hline Metal stent & Flexible bronchoscopic approach & Very difficult to remove \\
& Minimal stent migration & Malignant tissue can grow between stent mesh \\
& Resistant to external compression & Perforation of airway and damage to surrounding structures \\
Silicone stent & Repositioning and removal easily done & Rigid bronchoscopy and general anesthetic usually required \\
& Multiple stent deployment & Migration common \\
& & Tissue growth can obstruct distal or proximal end of stent \\
Hybrid stents & Flexible bronchoscopic approach & Most expensive \\
& Resistant to external compression & Difficult to remove or reposition \\
& Resists inward growth of malignant tissue & \\
\hline
\end{tabular}


also be used to close an aero-digestive fistula caused by malignancy (lung/esophageal carcinoma or occasionally lymphoma) [116118]. Malignancy involving the main carina is best treated with silicone stents designed for this anatomic location [119]. Metal stents are usually not placed in cases where they potentially need to be removed and thus are usually contraindicated in benign disease and more suitable for palliation, however, selfexpanding metal stents have recently been removed using cryotherapy [120]. Indications for stent removal include excessive or recurrent tumor formation causing obstruction, recurrence of malignant stenosis after stent failure, stent fracture, and accomplishment of treatment [120, 121].

It is advisable that a stenotic lesion should be dilated or debrided as far as safely possible to get the best possible benefit from stent insertion. Bronchoscopic debridement of tumor is first performed to remove as much endoluminal obstruction as possible, and thus stent placement should be considered to maintain long-term airway patency. Even though bronchoscopy is frequently used to deploy airway stents, tracheobronchial stent insertion can be accomplished using fluoroscopic guidance alone [121]. The diameter of the stent should be about 1-2 mm greater than the estimated normal diameter of the airway. Stent sizing varies according to the airway and length of stenosis. Follow-up bronchoscopy is indicated if symptoms recur [122, 123]. Regarding symptom relief in MAO, seven studies are available with a variety of airway stents [82, 123-129]. In a series of 40 patients with MAO, the severe dyspnea index improved in 34 of 39 patients within $24 \mathrm{~h}$ of stent insertion [130]. In patients with acute respiratory failure due to malignant $\mathrm{MAO}$ requiring mechanical ventilation, stenting is associated with weaning from ventilatory support. In one series this was achieved in 14 of 26 patients with MAO, 21 of whom had malignancy [131]. A 2005 study of 172 stents placed in 140 patients with MAO was encouraging [132]. The mean follow-up period was around 150 days. There were 23 complications, including tumor ingrowth $(n=9)$, excessive granulation tissue $(n=7)$, stent migration $(n=5)$, and restenosis $(n=2)$. Five of the complications occurred during the short-term period ( $<30$ days), with the remaining complications $(n=18)$ occurring after 30 days. Their results were very encouraging and they concluded that tracheobronchial stents offer minimally invasive palliative therapy for patients with incurable and unresectable MAO. The major drawback is excessive granulation tissue and tumor ingrowth, which occur primarily after 30 days [132].

Contraindications to airway stenting are the general contraindications to flexible bronchoscopy and whether any further therapy with either APC, endobronchial electrocautery, or laser therapy is planned as they can burn and break stents. External beam radiation and brachytherapy are not contraindications to airway stenting. Bioabsorbable airway stents and improved techniques for placement and removal of tracheobronchial stents may provide definitive improvements to the standard stenting currently used. The complications of stents pertain to the usual risks of bronchoscopy and general anesthetic, infection, perforation, aerodigestive fistula formation, mucous plugging, and stent migration and obstruction. The major complications of airway stenting can be divided into immediate and long term. Immediate complications are those relating to bronchoscopy itself, hemorrhage and 
pneumothorax. Long-term complications include metal fatigue causing broken mesh, stent migration which can cause obstruction, and secretion retention predisposing to hypoxia and infection. Airway perforation can occur if the stent erodes through an airway or tumor. Fistula formation after stent placement is a long-term complication of stent placement [133-136]. Razi et al. [124] found that timely stenting of the airway, before the morbid complications of malignant central airway obstruction have set in, resulted in improved survival. A recent single center retrospective review of MAO compared complication rates in 72 patients with and without stent insertion [12]. The majority of stents placed were either self-expandable metal or hybrid stents. There were more infections in those in whom stents were placed. The authors concluded that a strategy of initially holding off on stent placement should be considered in those patients with removal of airway obstruction who may respond to external beam radiation and/or chemotherapy [12].

In summary, after removal of endobronchial obstruction through debulking, stents can be considered to maintain airway patency [6-8]. Self-expandable metal stents should not be placed in patients where removal is considered in the future.

\section{CONCLUSION}

In conclusion, we have highlighted the bronchoscopic options for treatment of MAO, including immediate and delayed effect modalities and maintaining patency with bronchoscopy. Although the majority of patients undergoing bronchoscopic removal of MAO have advanced disease, improvement in patient symptoms is often immediate and satisfactory for both patient and bronchoscopist alike. Patient selection should exclude patients with short life expectancy, limited symptoms, and inability to visualize beyond the obstruction. The decision to treat should be made with consideration of other modalities, such as external beam radiation in a multidisciplinary setting.

\section{ACKNOWLEDGMENTS}

No funding or sponsorship was received for this study or publication of this article. All named authors meet the ICMJE criteria for authorship for this manuscript, take responsibility for the integrity of the work as a whole, and have given final approval for the version to be published.

Conflict of interest. P D. Mitchell and M. P. Kennedy declare that they have no conflict of interest.

Compliance with ethics guidelines. This review article is based on previously conducted studies, and does not involve any new studies of human or animal subjects performed by any of the authors.

\section{REFERENCES}

1. Zöllner F. Gustav Killian, father of bronchoscopy. Arch Otolaryngol. 1965;82(6):656-9.

2. Coates GM. Chevalier Jackson, 1865-1958. AMA Arch Otolaryngol. 1959;69(3):372-4.

3. Prakash U. "Never give up": professor Shigeto Ikeda, 1925-2001. J Bronchol. 2002;9(2):83-4.

4. Siegel R, Naishadham D, Jemal A. Cancer statistics, 2013. CA Cancer J Clin. 2013;63(1):11-30.

5. Cancer principles and practice of oncology. Philadelphia: JB Lipincott; 1989. pp. 591-705. 
6. Du Rand IA, Barber PV, Goldring J, et al. British Thoracic Society guideline for advanced diagnostic and therapeutic flexible bronchoscopy in adults. Thorax. 2011;66(Suppl 3):1-21.

7. Bolliger CT, Mathur PN, Beamis JF, et al. ERS/ATS statement on interventional pulmonology. Eur Respir J. 2002;19:356-73.

8. ACCP 2013 guidelines symptom management in patients with lung cancer diagnosis and management of lung cancer, 3rd ed. American College of Chest Physicians Evidence-Based Clinical Practice Guidelines; 2013. pp. 468-469.

9. Rodrigues G, Videtic GMM, Sur R, et al. Palliative thoracic radiotherapy in lung cancer: an American society for radiation oncology evidence-based clinical practice guideline. Pract Radiat Oncol. 2011;1(2):60-71.

10. Oviatt PL, Stather DR, Michaud G, Maceachern P, Tremblay A. Exercise capacity, lung function, and quality of life after interventional bronchoscopy. J Thorac Oncol. 2011;6(1):38-42.

11. Amjadi K, Voduc N, Cruysberghs Y, et al. Impact of interventional bronchoscopy on quality of life in malignant airway obstruction. Respiration. 2008;76(4):421-8.

12. Grosu HB, Eapen GA, Morice RC, et al. Stents are associated with increased risk of respiratory infections in patients undergoing airway interventions for malignant airways disease. Chest. 2013;144(2):441-9.

13. Temel JSI, Greer JA, Muzikansky A, et al. Early palliative care for patients with metastatic nonsmall-cell lung cancer. $\mathrm{N}$ Engl J Med. 2010;363(8):733-42.

14. Chhajed PN, Baty F, Pless M, Somandin S, Tamm $\mathrm{M}$, Brutsche $\mathrm{MH}$. Outcome of treated advanced non-small cell lung cancer with and without central airway obstruction. Chest. 2006;130(6):1803-7.

15. Chhajed PN, Eberhardt R, Dienemann $\mathrm{H}$, et al. Therapeutic bronchoscopy interventions before surgical resection of lung cancer. Ann Thorac Surg. 2006;81(5):1839-43.

16. Rodrigues AJ, Oliveira EQ, Scordamaglio PR, Gregório MG, Jacomelli M, Figueiredo VR. Flexible bronchoscopy as the first-choice method of removing foreign bodies from the airways of adults. J Bras Pneumol. 2012;38(3):315-20.

17. Dutau H, Vandemoortele T, Breen DP. Rigid bronchoscopy. Clin Chest Med. 2013;34(3):427-35.
18. Suratt P, Smiddy J, Gruber B. Deaths and complications associated with fiberoptic bronchoscopy. Chest. 1976;69:747-51.

19. Ginsberg RJ, Vokes EE, Ruben A. Non-small cell lung cancer. In: De Vita VT, Hellman S, Rosenburg SA, editors. Cancer, principles and practices of oncology. 5th ed. Philadelphia: Lippincott-Raven; 1997. p. 858-911.

20. Strauss AA, Strauss SF, Crawford RA. Surgical diathermy of carcinoma of the rectum. JAMA. 1935;104:1480.

21. Soulas, A, Mounier-Kuhn, P. Bronchologie. Masson Ed, Paris, 1956, pp. 703-704.

22. Sutedja G, van Kralingen K, Schramel FM, Postmus PE. Fibre optic bronchoscopic electrosurgery under local anaesthesia for rapid palliation in patients with central airway malignancies: a preliminary report. Thorax. 1994;49(12):1243.

23. Coulter TD, Mehta AC. The heat is on: impact of endobronchial electrosurgery on the need for $\mathrm{Nd}-$ YAG laser photoresection. Chest. 2000;118:516-21.

24. Hooper RG, Jackson FN. Endobronchial electrocautery. Chest. 1985;87(6):712.

25. Vonk-Noordegraaf A, Postmus PE, Sutedja TG. Bronchoscopic treatment of patients with intraluminal microinvasive radiographically occult lung cancer not eligible for surgical resection: a follow-up study. Lung Cancer. 2003;39(1):49.

26. Frizzelli R. Treatment by electrocoagulation in malignant tracheobronchial pathology. Rev Pneumol Clin. 1986;42(5):235.

27. van Boxem TJ, Venmans BJ, Schramel FM, et al. Radiographically occult lung cancer treated with fibreoptic bronchoscopic electrocautery: a pilot study of a simple and inexpensive technique. Eur Respir J. 1998;11(1):169.

28. Platt RC. Argon plasma electrosurgical coagulation. Biomed Sci Instrum. 1997;34:332.

29. Zhao W, Yang Z, Chen LA. Etiological diagnosis and treatment of central airway obstruction: report of 40 cases and review of the literature (in Chinese). Zhonghua Jie $\mathrm{He} \mathrm{He} \mathrm{Hu} \mathrm{Xi}$ Za Zhi. 2011;34(8):590-4.

30. Colchen A, Fischler M. Emergency interventional bronchoscopies. Rev Pneumol Clin. 2011;67(4):209-13.

31. Yang $\mathrm{H}$, Yang $\mathrm{H}$, Zhou $\mathrm{Y}, \mathrm{Qu} \mathrm{S}, \mathrm{Hu} \mathrm{C}$. Bronchoscopic argon plasma coagulation therapy 
for bronchial carcinoma. Zhong Nan Da Xue Xue Bao Yi Xue Ban. 2009;34(7):651-4.

32. Reddy C, Majid A, Michaud G, et al. Gas embolism following bronchoscopic argon plasma coagulation: a case series. Chest. 2008;134(5):1066-9.

33. Osseiran K, Barchfeld T, Dellweg D, Haidl P. Cerebral arterial gas embolism as complication during the therapeutic endobronchial use of argon plasma coagulation. Pneumologie. 2008;62(6):353-4.

34. Reichle G, Freitag L, Kullmann HJ, Prenzel R, Macha HN, Farin G. Argon plasma coagulation in bronchology: a new method-alternative or complementary? Pneumologie. 2000;54(11):508.

35. Morice RC, Ece T, Ece F, Keus L. Endobronchial argon plasma coagulation for treatment of hemoptysis and neoplastic airway obstruction. Chest. 2001;119(3):781.

36. Crosta C, Spaggiari L, De Stefano A, Fiori G, Ravizza D, Pastorino U. Endoscopic argon plasma coagulation for palliative treatment of malignant airway obstructions: early results in 47 cases. Lung Cancer. 2001;33(1):75.

37. Capaccio P, Peri A, Fociani P, Ferri A, Ottaviani F. Flexible argon plasma coagulation treatment of obstructive tracheal metastatic melanoma. Am J Otolaryngol. 2002;23(4):253-5.

38. Strong MS, Jako GJ, Polanyi T, et al. Laser surgery in the aerodigestive tract. Am J Surg. 1973;126:529-33.

39. Brutinel WM, Cortese DA, Mcdougall JC, et al. A two-year experience with the neodymium-YAG laser in endobronchial obstruction. Chest. 1987;91:159-65.

40. Dedhia HV, Lapp NL, Jain PR, et al. Endoscopic laser therapy for respiratory disorders due to obstructive airway tumours. Crit Care Med. 1985;13:464-7.

41. Cavaliere S, Venuta F, Foccoli P, Toninelli C, La Face B. Endoscopic treatment of malignant airway obstructions in 2,008 patients. Chest. 1996;110(6):1536.

42. Scherer TA. Nd-YAG laser ignition of silicone endobronchial stents. Chest. 2000;117:1449.

43. Ossoff RH, Duncavage JA, Eisenman TS, Karlan MS. Comparison of tracheal damage from laserignited endotracheal tube fires. Ann Otol Rhinol Laryngol. 1983;92:333.
44. Rosenberg C, Puls R, Hegenscheid K, et al. Laser ablation of metastatic lesions of the lung: longterm outcome. AJR Am J Roentgenol. 2009;192(3):785-92.

45. Prakash US. Bronchoscopy. In: Mason RJ, Broaddus VC, Murray JF, editors. Murray and Nadel's textbook of respiratory medicine. 4th ed. Philadelphia: Elsevier; 2005. p. 1617-50.

46. Taber SW, Buschemeyer WC 3rd, Fingar VH, Wieman TJ. The treatment of malignant endobronchial obstruction with laser ablation. Surgery. 1999;126(4):730-3.

47. Cavaliere S, Foccoli P, Farina PL. Nd:YAG laser bronchoscopy. A five-year experience with 1,396 applications in 1,000 patients. Chest. 1988;94:15-21.

48. Cavaliere F, Dumon JF. Laser bronchoscopy. In: Bollinger CT, Mathur PN, editors. Interventional bronchoscopy. Basel: Karger AG; 2000. p. 108.

49. Han CC, Prasetyo D, Wright GM. Endobronchial palliation using Nd:YAG laser is associated with improved survival when combined with multimodal adjuvant treatments. J Thorac Oncol. 2007;2(1):59-64.

50. Stout R, Barber P, Burt P, et al. Clinical and quality of life outcomes in the first United Kingdom randomized trial of endobronchial brachytherapy (intraluminal radiotherapy) vs. external beam radiotherapy in the palliative treatment of inoperable non-small cell lung cancer. Radiother Oncol. 2000;56(3):323-7.

51. Minnich DJ, Bryant AS, Dooley A, Cerfolio RJ. Photodynamic laser therapy for lesions in the airway. Ann Thorac Surg. 2010;89(6):1744-8.

52. Simoni P, Peters GE, Magnuson JS, Carroll WR. Use of the endoscopic microdebrider in the management of airway obstruction from laryngotracheal carcinoma. Ann Otol Rhinol Laryngol. 2003;112:11-3.

53. Kennedy MP, Rodolfo C, Morice RC, Carlos A, Jimenez CA, Eapen GA. Treatment of bronchial airway obstruction using a rotating tip microdebrider: a case report. J Cardiothorac Surg. 2007;26(2):16.

54. Lunn W, Garland R, Ashiku S, Thurer RL, FellerKopman D, Ernst A. Microdebrider bronchoscopy: a new tool for the interventional bronchoscopist. Ann Thorac Surg. 2005;80:1485-8.

55. Ernst A, Anantham D. Update on interventional bronchoscopy for the thoracic radiologist. J Thorac Imaging. 2011;26(4):263-77. 
56. Arnott J. On the treatment of cancer through the regulated application of an anaesthetic temperature. London: J. Churchill; 1851. p. 32.

57. Eichler B, Savy FP, Melloni B, Germouty JD. Désobstruction tumorale par cryothérapie souple (Tumoral tracheobronchial deobstruction by cryotherapy using a flexible catheter). Presse Med. 1988;17:2138-9.

58. Sanderson DR, Neel HB, Payne WS, Woolner LB. Cryotherapy for bronchogenic carcinoma: report of a case. Mayo Clin Proc. 1975;50(8):435-7.

59. Maiwand MO. Cryotherapy for advanced carcinoma of the trachea and bronchi. Br Med J (Clin Res Ed). 1986;293(6540):181-2.

60. Vergnon J, Huber M, Moghissi K. Place of cryotherapy, brachytherapy and photodynamic therapy in therapeutic bronchoscopy of lung cancers. ERJ. 2006;28(1):200-18.

61. Deygas N, Froudarakis M, Ozenne G, Vandevenne A, Fournel P, Vergnon JM. Cryotherapy in early superficial bronchogenic carcinoma. Chest. 2001;120:26-31.

62. Theodorescu D. Cancer cryotherapy: evolution and biology. Rev Urol. 2004;6(suppl 4):S9-19.

63. Bertoletti L, Elleuch R, Kaczmarek D, Jean-François $\mathrm{R}$, Vergnon JM. Bronchoscopic cryotherapy treatment of isolated endoluminal typical carcinoid tumor. Chest. 2006;130(5):1405-11.

64. Hetzel M, Hetzel J, Schumann C, et al. Cryorecanalization: a new approach for the immediate management of acute airway obstruction. J Thorac Cardiovasc Surg. 2004; 127:1427e31.

65. Zafer Aktas Z, Ersin Gunay E, Nevin E, et al. Endobronchial cryobiopsy or forceps biopsy for lung cancer diagnosis. Ann Thorac Med. 2010;5(4):242-6.

66. Sheski FD, Mathur PN. Diagnosis and treatment of early lung cancer: as it stands today. Semin Respir Crit Care Med. 2004;25(4):387-97.

67. Schumann C, Lepper PM, Barth TF, et al. Successful immediate cryorecanalization of a simultaneous high-grade tracheal and bronchial stenosis as rare manifestations of bronchialassociated lymphoid tissue lymphoma. J Thorac Cardiovasc Surg. 2009;137(1):e17-9.

68. Suvatne J, Browning R. Combination bronchoscopic Nd:YAP laser and cryotherapy management of inoperable metastatic tracheobronchial tree adenoid cystic carcinoma.
In: American thoracic society meeting 2010. http://www.atsjournals.org/doi/book/10.1164/ ajrccm-conference.2010.A043

69. Niu L, Xu K, Mu F. Cryosurgery for lung cancer. J Thorac Dis. 2012;4(4):408-19.

70. Lee SH, Choi WJ, Sung SW, et al. Endoscopic cryotherapy of lung and bronchial tumors: a systematic review. Korean J Intern Med. 2011;26(2):137-44.

71. Maiwand MO, Evans JM, Beeson JE. The application of cryosurgery in the treatment of lung cancer. Cryobiology. 2004;48(1):55-61.

72. Gompelmann DI, Eberhardt R, Herth FJ. Advanced malignant lung disease: what the specialist can offer. Respiration. 2011;82(2):111-23.

73. Yankauer S. Two cases of lung tumor treated bronchoscopically. N Y Med J. 1922;21:741.

74. Kernan JD. Treatment with radon implantation and diathermy; carcinoma of the lung and bronchus. Arch Otolaryngol. 1933;17:467.

75. Henschke UK, Hilaris BS, Mahan GD. Remote afterloading with intracavitary applicators. Radiology. 1964;83:344-5.

76. Derhem N, Sabila H. Endobronchial brachytherapy: state of the art in 2013. Cancer Radiother. 2013;17(2):162-5.

77. Raben A, Mychalczak B. Brachytherapy for nonsmall cell lung cancer and selected neoplasms of the chest (in French). Chest. 1997;112:276S.

78. Schray MF, McDougall JC, Martinez A, et al. Management of malignant airway compromise with laser and low dose rate brachytherapy. The Mayo Clinic experience. Chest. 1988;93:264.

79. Nori D, Allison R, Kaplan B, et al. High dose-rate intraluminal irradiation in bronchogenic carcinoma. Technique and results. Chest. 1993;104:1006.

80. Taulelle M, Chauvet B, Vincent P, et al. High dose rate endobronchial brachytherapy: results and complications in 189 patients. Eur Respir J. 1998;11:162.

81. Guarnaschelli JN, Jose BO. Palliative high-doserate endobronchial brachytherapy for recurrent carcinoma: the University of Louisville experience. J Palliat Med. 2010;13:981.

82. Kennedy MP, Jimenez CA, Chang J, et al. Optimization of bronchial brachytherapy catheter placement with a modified airway stent. Eur Respir J. 2008;31(4):902-3. 
83. Rochet N, Hauswald H, Stoiber EM, et al. Primary radiotherapy with endobronchial high-dose-rate brachytherapy boost for inoperable lung cancer: long-term results. Tumori. 2013;99(2):183-90.

84. Khanavkar B, Stern P, Alberti W, Nakhosteen JA. Complications associated with brachytherapy alone or with laser in lung cancer. Chest. 1991;99:1062.

85. Cardona AF, Reveiz L, Ospina EG, et al. Palliative endobronchial brachytherapy for non-small cell lung cancer. Cochrane Database Syst Rev. 2008;2:CD004284.

86. Kelly JF, Delclos ME, Morice RC, Huaringa A, Allen $\mathrm{PK}$, Komaki R. High-dose-rate endobronchial brachytherapy effectively palliates symptoms due to airway tumors: the 10-years M.D. Anderson cancer center experience. Int J Radiat Oncol Biol Phys. 2000;48:697-702.

87. Aumont-le Guilcher M, Prevost B, Sunyach MP, et al. High-dose-rate brachytherapy for non-smallcell lung carcinoma: a retrospective study of 226 patients. Int $\mathrm{J}$ Radiat Oncol Biol Phys. 2011;79:1112.

88. Huber RM, Fischer R, Hautmann H, Pollinger B, Häußinger $\mathrm{K}$, Wendt $\mathrm{T}$. Does additional brachytherapy improve the effect of external irradiation? A prospective, randomized study in central lung tumors. Int J Radiat Oncol Biol Phys. 1997;38:533-40.

89. Hemandez P, Gursahaney A, Roman T, et al. High dose rate brachytherapy for the local control of endobronchial carcinoma following external irradiation. Thorax. 1996;51:354-8.

90. Langendijk H, de Jong J, Tjwa M, et al. External irradiation versus external irradiation plus endobronchial brachytherapy in inoperable nonsmall cell lung cancer: a prospective randomized study. Radiother Oncol. 2001;58(3):257-68.

91. Niemoeller OM, Pöllinger B, Niyazi M, et al. Mature results of a randomized trial comparing two fractionation schedules of high dose rate endoluminal brachytherapy for the treatment of endobronchial tumors. Radiat Oncol. 2013;8:8.

92. Miller RR, McGregor DH. Hemorrhage from carcinoma of the lung. Cancer. 1980;46:200-5.

93. Von Tappeiner $\mathrm{H}$, Jesionek A. Therapeutische versuche mit floureszierenden stoffen. Muench Med Wschrf. 1903;47:2042.

94. Allison RR. Photodynamic therapy: oncologic horizons. Future Oncol. 2014;10(1):123-4. doi:10. 2217/fon.13.176.
95. McCaughan JS Jr, Hawley PC, LaRosa JC, et al. Photodynamic therapy to control life-threatening hemorrhage from hereditary hemorrhagic telangiectasia. Lasers Surg Med. 1996;19:492.

96. Hyata Y, Kato H, Kanoka C, et al. Fiberoptic bronchoscopic laser photo-radiation for tumour localisation in lung cancer. Chest. 1982;82:10-4.

97. Dougherty TJ. Hematoporphyrin derivative for detection and treatment of cancer. J Surg Oncol. 1980;15:209.

98. Gomer CJ, Dougherty TJ. Determination of [3H]and $[14 \mathrm{C}]$ hematoporphyrin derivative distribution in malignant and normal tissue. Cancer Res. 1979;39:146.

99. Moghissi K, Dixon K. Is bronchoscopic photodynamic therapy a therapeutic option in lung cancer? Eur Respir J. 2003;22:535-41.

100. McCaughan JS Jr. Photodynamic therapy of endobronchial and esophageal tumors: an overview. J Clin Laser Med Surg. 1996;14:223.

101. Kato H, Okunaka T, Shimatani H. Photodynamic therapy for early stage bronchogenic carcinoma. J Clin Laser Med Surg. 1996;14:235.

102. Cortese DA, Edell ES, Kinsey JH. Photodynamic therapy for early stage squamous cell carcinoma of the lung. Mayo Clin Proc. 1997;72:595.

103. Agostinis $\mathrm{P}$, Berg $\mathrm{K}$, Cengel KA, et al. Photodynamic therapy of cancer. An update. CA Cancer J Clin. 2011;61(4):250-81.

104. Maziak DE, Markman BR, MacKay JA, et al. Photodynamic therapy in nonsmall cell lung cancer: a systematic review. Ann Thorac Surg. 2004;77:1484.

105. Endo C, Miyamoto A, Sakurada A, et al. Results of long-term follow-up of photodynamic therapy for roentgenographically occult bronchogenic squamous cell carcinoma. Chest. 2009;136:369.

106. McCaughan JS Jr. Survival after photodynamic therapy to non-pulmonary metastatic endobronchial tumors. Lasers Surg Med. 1999;24:194.

107. Ikeda N, Usuda J, Kato H, et al. New aspects of photodynamic therapy for central type early stage lung cancer. Lasers Surg Med. 2011;43(7):749-54.

108. McCaughan JS Jr, Williams TE. Photodynamic therapy for endobronchial malignant disease: a prospective fourteen-year study. J Thorac Cardiovasc Surg. 1997;114(6):940-6. 
109. Diaz-Jiménez JP, Martínez-Ballarín JE, Llunell A, et al. Efficacy and safety of photodynamic therapy versus Nd-YAG laser resection in NSCLC with airway obstruction. Eur Respir J. 1999;14:800.

110. Freitag L, Ernst A, Thomas M, et al. Sequential photodynamic therapy (PDT) and high dose brachytherapy for endobronchial tumour control in patients with limited bronchogenic carcinoma. Thorax. 2004;59:790.

111. Santos RS, Raftopoulos Y, Keenan RJ, et al. Bronchoscopic palliation of primary lung cancer: single or multimodality therapy? Surg Endosc. 2004; 18:931.

112. Saad CP, Murthy S, Krizmanich G, et al. Selfexpandable metallic airway stents and flexible bronchoscopy: long-term outcomes analysis. Chest. 2003;124:1993-9.

113. Noppen M, Stratakos G, D'Haese J, Meysman M, Vinken W. Removal of covered self-expandable metallic airway stents in benign disorders: indications, technique, and outcomes. Chest. 2005;127(2):482-7.

114. Stockton PA, Ledson MJ, Hind CR, et al. Bronchoscopic insertion of Gianturco stents for the palliation of malignant lung disease: 10 year experience. Lung Cancer. 2003;42:113-7.

115. Walser EM. Stent placement for tracheobronchial disease. Eur J Radiol. 2005;55:321-30.

116. Chawla RK, Madan A, Chawla K. Tracheoesophageal fistula: successful palliation after failed esophageal stent. Lung India. 2012;29(3):289-92.

117. Karapolat S, Onen A, Sanli A. Tracheobronchial stenting for management of bronchopleural fistula. West Indian Med J. 2009;58(1):76.

118. Wang CY, Chou CH, Wang HP, Chen JS, Lee P. Successful treatment of bronchoesophageal fistula with esophageal and bronchial stenting. J Formos Med Assoc. 2011;110(4):270-2.

119. Dutau H, Toutblanc B, Lamb C, et al. Use of the Dumon Y-stent in the management of malignant disease involving the carina: a retrospective review of 86 patients. Chest. 2004;126:951-8.

120. Majid A, Palkar A, Myers R, Berger RL, Folch E. Cryotechnology for staged removal of selfexpandable metallic airway stents. Ann Thorac Surg. 2013;96(1):336-8.

121. Herth F, Becker HD, LoCicero J III, et al. Successful bronchoscopic placement of tracheobronchial stents without fluoroscopy. Chest. 2001;119:1910-2.
122. Miyazawa T, Miyazu Y, Iwamoto Y, et al. Stenting at the flow-limiting segment in tracheobronchial stenosis due to lung cancer. Am J Respir Crit Care Med. 2004;169:1096.

123. Lemaire A, Burfeind WR, Toloza E, et al. Outcomes of tracheobronchial stents in patients with malignant airway disease. Ann Thorac Surg. 2005;80:434.

124. Razi SS, Lebovics RS, Schwartz G, et al. Timely airway stenting improves survival in patients with malignant central airway obstruction. Ann Thorac Surg. 2010;90(4):1088-93.

125. Ferrell B, Koczywas M, Grannis F, Harrington A. Palliative care in lung. Cancer Surg Clin N Am. 2011;91(2):403-ix.

126. Bolliger CT, Breitenbuecher A, Brutsche M, Heitz M, Stanzel F. Use of studded Polyflex stents in patients with neoplastic obstructions of the central airways. Respiration. 2004;71(1):83-7.

127. Bolliger CT, Probst R, Tschopp $\mathrm{K}$, Solèr $\mathrm{M}$, Perruchoud AP. Silicone stents in the management of inoperable tracheobronchial stenoses. Indications and limitations. Chest. 1993;104(6):1653-9.

128. Wilson GE, Walshaw MJ, Hind CR. Treatment of large airway obstruction in lung cancer using expandable metal stents inserted under direct vision via the fibreoptic bronchoscope. Thorax. 1996;51(3):248-52.

129. Bolliger CT, Heitz M, Hauser R, Probst R, Perruchoud AP. An airway wallstent for the treatment of tracheobronchial malignancies. Thorax. 1996;51(11):1127-9.

130. Monnier P, Mudry A, Stanzel F, et al. The use of the covered wallstent for the palliative treatment of inoperable tracheobronchial cancers. A prospective, multicenter study. Chest. 1996;110:1161e8.

131. Lin SM, Lin TY, Chou CL, et al. Metallic stent and flexible bronchoscopy without fluoroscopy for acute respiratory failure. Eur Respir J. 2008;31:1019e23.

132. Ibrahim E. Bronchial stents. Ann Thorac Med. 2006;1:92-7.

133. de Mello-Filho FV, Antonio SM, Carrau RL. Endoscopically placed expandable metal tracheal stents for the management of complicated tracheal stenosis. Am J Otolaryngol. 2003;24:34.

134. Gaissert HA, Grillo HC, Wright CD, et al. Complication of benign tracheobronchial 
strictures by self-expanding metal stents. J Thorac Cardiovasc Surg. 2003;126:744.

135. Zakaluzny SA, Lane JD, Mair EA. Complications of tracheobronchial airway stents. Otolaryngol Head Neck Surg. 2003;128:478.
136. Lunn W, Feller-Kopman D, Wahidi M, Ashiku S, Thurer R, Ernst A. Endoscopic removal of metallic airway stents. Chest. 2005;127:2106-12. 